Utah State University

DigitalCommons@USU

$5-1978$

\title{
The Combined Effects of Air Temperature, Wind, and Radiation on the Resting Metabolism of Avian Raptors
}

Steven R. Hayes

Utah State University

Follow this and additional works at: https://digitalcommons.usu.edu/etd

Part of the Biology Commons

\section{Recommended Citation}

Hayes, Steven R., "The Combined Effects of Air Temperature, Wind, and Radiation on the Resting Metabolism of Avian Raptors" (1978). All Graduate Theses and Dissertations. 8053.

https://digitalcommons.usu.edu/etd/8053

This Dissertation is brought to you for free and open access by the Graduate Studies at DigitalCommons@USU. It has been accepted for inclusion in All Graduate Theses and Dissertations by an authorized administrator of DigitalCommons@USU. For more information, please contact digitalcommons@usu.edu.

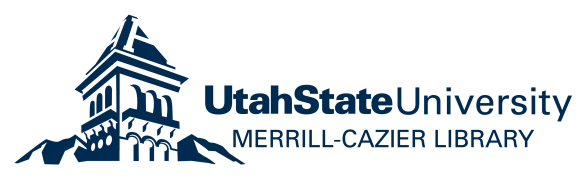


THE COMBINED EFFECTS OF AIR TEMPERATURE, WIND, AND RADIATION

ON THE RESTING METABOLISM OF AVIAN RAPTORS

by

Steven R. Hayes

A dissertation submitted in partial fulfillment

of the requirements for the degree

of

DOCTOR OF PHILOSOPHY

in

Biology

Approved:

Major Professor

Committee Member

Committee Member

Committee Member

Committee Member

Dean of Graduate Studies

UTAH STATE UNIVERSITY

Logan, Utah

1978 


\section{ACKNOWLEDGMENTS}

This research was supported in part by NSF Grant PCM 75-19442 and by the Department of Biology, Utah State University.

I would like to thank my major professor, Dr. James A. Gessaman, for his guidance and encouragement during this study. My appreciation is also extended to my Graduate Committee (professors James A. MacMahon, LeGrande C. Ellis, Russel M. Holdredge, and Inge Dirmhirn) for their critical review of the manuscript.

I would also like to thank Dr. Warren P. Porter for his help in developing the heat transfer section of the manuscript and for his gracious hospitality while I was visiting and working in his laboratory at the University of Wisconsin.

Finally, I extend a husband's gratitude to a loving wife who has shared the triumphs and disappointments of my graduate study. 
ACKNOWLEDGMENTS . . • . . . . . . . . . . . . . . . . . . . . .

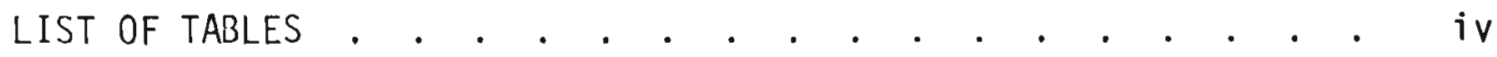

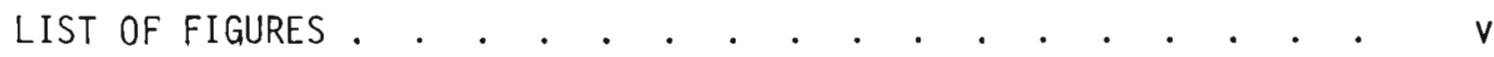

ABSTRACT • . . . . . . . . . . . . . . . . . . . . . . . vi

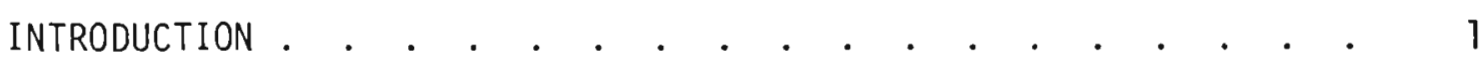

METHODS . . . . . . . . . . . . . . . . . . . . . . 3

The combined effects of air temperature, wind and radiation . . . . . . . . . . . . . . . . 3

Heat transfer analysis . . . . . . . . . . . . . 6

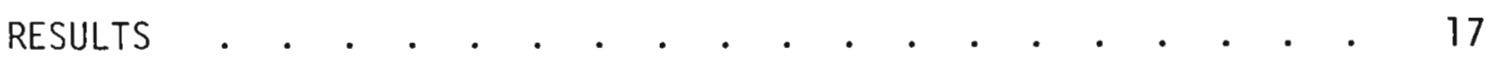

The combined effects of air temperature, wind and radiation

Heat transfer analysis . . . . . . . . . . . . . 27

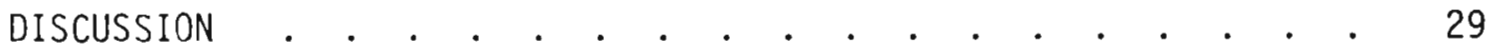

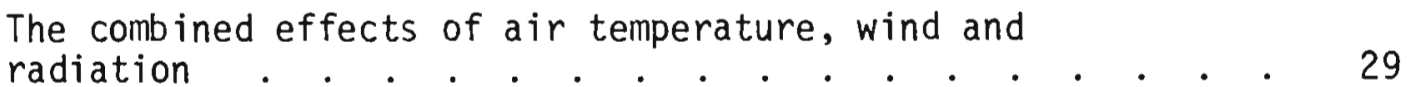

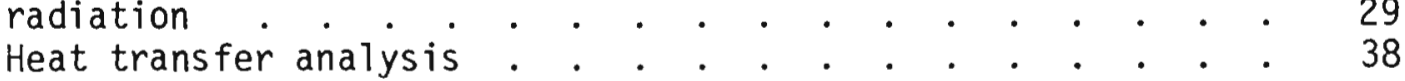

CONCLUSIONS . . . . . . . . . . . . . . . . . . . . . . . . . . . 40

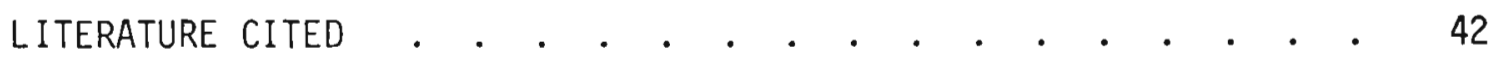

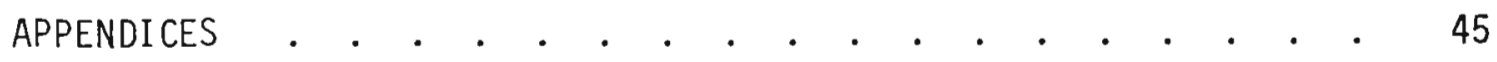

Appendix A . . . . . . . . . . . . . . . . . . 46

Appendix B . . . . . . . . . . . . . . . . . 48

Appendix C . . . . . . . . . . . . . . . . . . . . 49

VITA . . . . . . . . . . . . . . . . . . . . 50 


\section{L.IST OF TABLES}

Table

Page

1 Nomenclature used in heat transfer analysis... . . 7

2 Comparison of measured metabolism values with metabolism values predicted by the individual multiple regression equations and with the heat 


\section{LIST OF FIGURES}

Figure

Page

1 Cylinder model of birds for heat transfer analysis. .

2 Least square means and standard errors summarizing for all birds (A) the effect of wind on weight specific metabolism at five radiation loads and (B) the effect of radiation on weight specific metabolism at four wind speeds. . . . . . . .

3 Least square means and standard errors summarizing (A) the effect of wind and (B) the effect of radiation on the weight relative metabolism of the three size classes of raptors. . . . . . . . .

4 Least square means and standard errors summarizing the metabolic reducing power of radiation on the three size classes of raptors. . . . . . . .

5 Least square regression lines illustrating the change in metabolism due to radiation $(0.0$ and $1.5 \mathrm{cal} \mathrm{cm}^{-2} \mathrm{~min}^{-1}$ ) over the range of air temperatures $(-17$ to $+34 \mathrm{C})$ for American kestrels, red-tailed hawks, and golden eagles. Extension of the thermoneutral zone and shift in the lower critical temperature due to radiation and body size is also shown. . . . . . . . . . . . . 


\section{ABSTRACT}

The Combined Effects of Air Temperature, Wind, and Radiation on the Resting Metabolism of Avian Raptors

by

Steven R. Hayes, Doctor of Philosophy

Utah State University, 1978

Major Professor: Dr. James A. Gessaman

Department: Biology

American kestrels, Falco sparverius; red-tailed hawks, Buteo jamaicensis; and golden eagles, Aquila chrysaetos, were perched in a wind tunnel and subjected to various combinations of air temperature, wind, and radiation. Oxygen consumption was measured under the various combinations of environmental variables, and multiple regression equations were developed to predict resting metabolism as a function of body mass, air temperature, wind speed, and radiation load. Heat transfer analysis of the bird-thermal environment relationship was conducted to produce a biophysical model describing resting metabolism as a function of feather thermal conductance.

Because of differences in surface area to mass ratios and in average feather thicknesses among the three bird species, increases in metabolism due to wind ranged from non-linear in kestrels to linear in eagles. The relationship between wind speed and metabolic increase in red-tails was more linear than in kestrels. Wind speeds below 4.47 $\mathrm{m} \mathrm{sec}^{-1}$ produced relatively greater increases in metabolism than wind speeds above $4.47 \mathrm{~m} \mathrm{sec}^{-1}$. Changes in metabolism due to wind effects 
are discussed in terms of wind penetration of the feather coat and changes in boundary layer conditions. Ecological implications of cold weather conditions and their effect on kestrels are also discussed. Radiation produced linear decreases in metabolism at all wind speeds, and it extended the thermoneutral zone to lower air temperatures. Predictions of raptor resting metabolism based on multiple regression models and on heat transfer analysis were similar, but biophysical estimates paralleled actual values better than regression estimates. 


\section{INTRODUCTION}

Mechanisms of energy exchange between organisms and their environment should be studied with respect to their effect on actual metabolic heat levels that fluctuate in response to physical energy sources and sinks, e.g., solar isolation and convective cooling. Although it is obvious that heat exchange pathways are highly integrated and that variation in the flux of one mode will affect the intensity of another, studies of avian metabolism at various temperatures have been conducted in the absence of either strong isolation or wind or both. The effect of wind at various temperatures has been reported by Gessaman (1972) for snowy owls and by Robinson (1976), for white-crowned sparrows. Absorption of radiant energy as a metabolic heat-sparing mechanisms during exposure to cold air temperatures has been demonstrated with artificial sunlight during indirect calorimetric studies of black dyed zebra finches (Hamilton and Heppner, 1967; Heppner, 1970), brown-headed cowbirds (Lustick, 1969, 1971), greater roadrunners (Ohmart and Lasiewski, 1971), and whitecrowned sparrows (De Jong, 1976).

Energy budget analysis surfaced as an attempt to quantify the combined effects of environmental variables on total heat loss from an animal, to make useful ecological predictions from basic heat transfer theory, and to explore the relative role of each transfer pathway (Gates, 1962; Birkebak and Cremers, 1965; Birkebak, 1966; Bartlett and Gates, 1967; and Heller, 1972). Subsequently, the concept of climate spaces (Porter and Gates, 1969; Spotila, 1972) led to gross delineation of the livable environment, with respect to energy exchange parameters, for animals under steady state conditions. In a further attempt to quantify 
animal response to the environment in biophysical terms, Bakken and Gates (1975) and Bakken (1976) have revived the notion of operative environmental temperature as an index to the thermal environment that the surface of an animal "sees".

This paper is an attempt to empirically quantify the combined effects of air temperature, wind speed, and artificial sunlight on the resting metabolism of avian raptors over a wide range of body sizes (american kestrels $(115 \mathrm{~g})$, red-tailed hawks $(1145 \mathrm{~g})$, and golden eagles $(4320 \mathrm{~g})$, and to develop a simple model of heat transfer from the birds that expresses metabolism as a function of body mass, air temperature, wind speed, and radiation flux. The paper also examines the birds as thermal systems through heat transfer analysis, and it compares predicted metabolism values with actual values. 
METHODS

The combined effects of air temperature, wind and radiation

American kestrels and red-tailed hawks were trapped during winter months near Logan, Utah, and were housed indoors in $3 \times 3 \times 2.5 \mathrm{~m}$ environmental chambers. Light and mean temperature conditions approximated natural conditions. Golden eagles were borrowed from outdoor aviaries at Willow Park Zoo, Logan, Utah. Eagles were housed in the lab under the conditions described above. All birds were fed mice and rats or rabbits ad libitum. Adult male and female birds were used in the study (5 kestrels, 2 red-tails, and 4 eagles).

Wind speeds of $0.1,2.24,4.47$, and $13.42 \mathrm{~m} \mathrm{sec}^{-1}$ were generated in a $30 \mathrm{~m}$ long wind tunnel equipped with variable speed DC motor and aircraft propeller. An aerodynamically streamline perch was mounted on the floor of the working section of the tunnel $(4 \times 1.2 \times 1.2 \mathrm{~m})$ perpendicular to the air flow. The working section of the tunnel immediately followed a reducing section $(3 \times 3 \mathrm{~m}$ intake reduced to $1.2 \times 1.2 \mathrm{~m})$ so that air flow thru the working section had not achieved a true laminar condition. Because the intake was external to the wind tunnel building, environmental wind gusts were transmitted to the bird, also perturbing continuous laminar flow. Wind speed was calculated from velocity pressures measured with a micromanometer and pitot tubes. Experimental temperatures varied from -15 to $+34 \mathrm{C}$ depending on ambient conditions. Air temperature did not vary more than 3.2 C during acquisition of oxygen consumption data at any one wind speed.

Artificial solar radiation fluxes of $0.0,0.4,0.8,1.1$, and 1.5 cal $\mathrm{cm}^{-2} \mathrm{~min}^{-1}$ (equivalent to nighttime, early morning, late afternoon, bright overcast, and clear-solar noon isolation values, respectively) 
were produced with two General Electric infrared lamps (R-40, 250 watt, clear-end, color temperature $2500 \mathrm{~K}$ ) mounted on the ceiling of the wind tunnel directly above the perch. A Powerstat was used to adjust the radiation load to the desired levels. Although spectral emissions from these bulbs were shifted toward the infrared $\left(\lambda_{\max }=1.14 \mu \mathrm{m}\right)$ when compared to the solar spectrum, they produced heat loads comparable to environmental conditions but at longer wave lengths. The total absorbed radiation (cal min ${ }^{-1}$ ) was determined by two different methods. First, absorbed radiation (cal $\mathrm{cm}^{-2} \mathrm{~min}^{-1}$ ) was determined by two different methods. First, absorbed radiation (cal $\mathrm{cm}^{-2} \mathrm{~min}^{-1}$ ) was measured over the range 0.3 to $50.0 \mu \mathrm{m}$ with a Kahlsico net radiometer and Weston galvanometer at $2 \mathrm{~cm}$ intervals along the vertical height of each bird. Incremental absorbed radiation values were numbericalły integrated over their respective unit surface areas (the product of the hypotenuse of a right triangle of $2 \mathrm{~cm}$ height and the width of the bird's back within that $2 \mathrm{~cm}$ band). This technique assumes that the surface for absorption is flat. Although the dorsal surfaces of the birds are similar to hemicylinders, the cosine law of radiation makes this assumption reasonable. Second, incident direct, diffuse, and longwave radiation ( 0.3 to 50 . $\mu \mathrm{m}$ ) was measured at several heights along the vertical profile of each bird with the net radiometer equipped with a black hemispherical cup over the lower thermopile. This data was incorporated with spectral absorption data (collected with a Beckman DK-2 Spectrophotometer) from representative bird pelts and integrated over the surface area exposed to radiation to determine the total absorbed radiation. Surface areas and characteristic dimensions (e.g.; body circumference, body length, and dorsal silhouette area) of the birds were determined by the techniques described by Birkebak and Cremers 
(1965). See Appendix B for these values. Feather thicknesses were measured at one point on the breast and back with a blunt probe and millimeter rule.

Feather surface temperatures were measured at several points over the back and breast surfaces with a Barnes radiation thermometer and averaged to estimate back and breast surface temperatures, respectively. Skin temperatures were measured at one point on the back and on the breast with a copper-constantan thermocouple probe and a Leeds and Northrup Speedomax Thermocouple recorder.

The routine for oxygen consumption measurements was as follows: A bird was selected from the environmental chamber 12 to 18 hours after consumption of the last meal. It was weighed, transported approximately two miles, and loosely tethered to the perch in the wind tunnel. The bird was hooded, connected to the gas sample line, and allowed to become accustomed to ambient conditions (approximately one hour). Wind speed, selected at random, was then set. Once oxygen consumption stabilized, it was recorded for a fifteen minute period and was averaged to produce an oxygen consumption value for that wind speed, air temperature, and zero radiation regime. The radiation load was then set at $0.4 \mathrm{cal} \mathrm{cm}^{-2} \mathrm{~min}^{-1}$ and the procedure was repeated. After recording oxygen consumption at the five radiation levels, wind speed was again set at random with zero radiation. One replicate was considered to be oxygen consumption measured at all radiation levels at all wind speeds within one temperature band. The overall range of air temperature was arbitrarily divided into $10 \mathrm{C}$ bands, and at least three replicates were recorded for each species within each temperature band.

Oxygen consumption was measured with a Beckman G-2 paramagnetic analyzer in an open flow system similar to Depocas and Hart (1957) and King 
(1964). Modified falconers hoods with plastic bulbs attached anteriorly over the beak and connected to the sample line were used to collect respiratory gases. Ambient air was drawn into the system from around the edges of the mask and from small vent holes in the plastic bulb at rates sufficient to maintain the $\mathrm{F}_{\mathrm{EO}_{2}}$ (volume fraction of $\mathrm{O}_{2}$ ) between 0.18 and 0.20 to facilitate respiratory water loss. All birds were postabsorptive during oxygen consumption measurements, and an RQ of 0.76 was assumed (mean vaiue for raptors measured by James A. Gessaman, pers. comm.). A caloric conversion for an $R Q$ of $0.76\left(4.752 \mathrm{Kcal} / 1\right.$ iter $\left.\mathrm{O}_{2}\right)$ was used to compute energy metabolism (STP dry) (Lusk's Table, p. 310, Brody, 1945).

\section{Heat transfer analysis}

Table 1 is a listing of the nomenclature used in the heat transfer analysis. Figure 1 represents a cylinder model of the birds for heat transfer analysis. The energy balance equations describing the energy transfer through the skin surface,

$$
M-E_{r}=C_{f}\left(T_{S}-T_{f}\right)
$$

and the feather surface,

$$
C_{f}\left(T_{S}-T_{f}\right)+Q_{a b s}=h_{c} A\left(T_{f}-T_{a}\right)+\xi \sigma A\left(T_{f}^{4}-T_{a}{ }^{4}\right),
$$

describe the heat transfer analysis necessary to calculate $C_{f}$ and predict metabolism. Total thermal conductance of the feathers $\left(C_{f}\right)$ is derived from Fourier's Law. Under steady state conditions, the energy balance at the skin surface would be

$$
M-E_{r}=k A \frac{\left(T_{S}-T_{f}\right)}{\Delta x}
$$

However, neither the thermal conductivity of the feathers nor the average feather thickness is known. Thermal conductance combines both of these parameters and simplifies the analysis. 
Table 1. Nomenclature used in heat transfer analysis

\begin{tabular}{|c|c|c|}
\hline Symbol & Physical quantity & Units \\
\hline A & total surface area of bird & $\mathrm{cm}^{2}$ \\
\hline$A_{1}$ & breast surface area & $\mathrm{cm}^{2}$ \\
\hline$A^{2}$ & back surface area & $\mathrm{cm}^{2}$ \\
\hline$c_{f}$ & $\begin{array}{l}\text { total thermal conductance of the } \\
\text { feathers (general case) }\end{array}$ & cal $\min ^{-1}{ }^{0} K^{-1}$ \\
\hline $\mathrm{C}_{\mathrm{f}}$ & $\begin{array}{l}\text { total thermal conductance of the } \\
\text { feathers with zero radiation load }\end{array}$ & cal $\min ^{-1} o_{K^{-1}}$ \\
\hline $\mathrm{C}_{\mathrm{fl}}$ & $\begin{array}{l}\text { thermal conductance of breast } \\
\text { feathers with zero radiation load }\end{array}$ & cal $\min ^{-1} o_{K^{-1}}$ \\
\hline $\mathrm{C}_{\mathrm{f} 2_{0}}$ & $\begin{array}{l}\text { thermal conductance of back } \\
\text { feathers with zero radiation load }\end{array}$ & cal $\min ^{-1} o_{K^{-1}}$ \\
\hline $\mathrm{C}_{f_{r}}$ & $\begin{array}{l}\text { total thermal conductance of the } \\
\text { feathers with radiation load }\end{array}$ & cal $\min ^{-1} \mathrm{o}^{-1}$ \\
\hline$c_{f 1_{r}}$ & $\begin{array}{l}\text { thermal conductance of breast } \\
\text { feathers with radiation load }\end{array}$ & cal $\min ^{-1} \mathrm{o}_{\mathrm{K}^{-1}}$ \\
\hline $\mathrm{C}_{f 2}$ & $\begin{array}{l}\text { thermal conductance of back } \\
\text { feathers with radiation load }\end{array}$ & cal $\min ^{-1} \mathrm{o}^{-1}$ \\
\hline$E_{r}$ & energy lost in respiratory water & cal $\min ^{-1}$ \\
\hline$F_{0}$ & shape factor (bird to environment) & dimensionless \\
\hline$h_{c}$ & $\begin{array}{l}\text { convection heat transfer } \\
\text { coefficient }\end{array}$ & cal $\mathrm{cm}^{-2} \min ^{-1} \mathrm{o}_{K}^{-1}$ \\
\hline$h_{r}$ & $\begin{array}{l}\text { radiation heat transfer } \\
\text { coefficient }\end{array}$ & cal $\mathrm{cm}^{-2} \min ^{-1} 0_{K}^{-1}$ \\
\hline K & $\begin{array}{l}\text { thermal conductivity of the } \\
\text { feathers }\end{array}$ & cal $\mathrm{cm}^{-1} \min ^{-1} o_{K}^{-1}$ \\
\hline$M$ & metabolism & cal $\min ^{-1}$ \\
\hline$Q_{\text {sol ar }}$ & $\begin{array}{l}\text { all radiation incident on the } \\
\text { bird }\end{array}$ & cal $\mathrm{cm}^{-2} \min ^{-1}$ \\
\hline
\end{tabular}


Table 1. (continued)

Symbol Physical quantity Units

\begin{tabular}{|c|c|c|}
\hline$Q_{\text {abs }}$ & total absorbed radiation & cal $\min ^{-1}$ \\
\hline$r_{i 1}$ & body radius, breast & $\mathrm{cm}$ \\
\hline$r_{i 2}$ & body radius, back & $\mathrm{cm}$ \\
\hline$r_{01}$ & body + feather radius, breast & $\mathrm{cm}$ \\
\hline$r_{02}$ & body + feather radius, back & $\mathrm{cm}$ \\
\hline$s_{1}$ & $\begin{array}{l}\text { breast scale factor, based on the } \\
\text { relative thickness of the breast } \\
\text { and back feathers and the relative } \\
\text { surface areas of the breast and back }\end{array}$ & dimensionless \\
\hline$T_{a}$ & air temperature & ${ }^{o} K_{K}$ \\
\hline$T_{f}$ & $\begin{array}{l}\text { average surface temperature of } \\
\text { feathers (general case) }\end{array}$ & ${ }^{o} K$ \\
\hline$T_{f 1}$ & $\begin{array}{l}\text { surface temperature of breast } \\
\text { feathers with zero radiation load }\end{array}$ & ${ }^{o} k$ \\
\hline$\left.T_{f}\right]_{r}$ & $\begin{array}{l}\text { surface temperature of breast } \\
\text { feathers with radiation load }\end{array}$ & ${ }^{o} K_{K}$ \\
\hline$T_{f 2}$ & $\begin{array}{l}\text { surface temperature of back } \\
\text { feathers with radiation load }\end{array}$ & ${ }^{o} K_{K}$ \\
\hline $\mathrm{T}_{\mathrm{ST}}$ & $\begin{array}{l}\text { skin temperature of breast } \\
\text { with radiation load }\end{array}$ & $o_{K}$ \\
\hline $\mathrm{T}_{\mathrm{S}}$ & $\begin{array}{l}\text { skin temperature of back with zero } \\
\text { radiation load }\end{array}$ & ${ }^{o} K$ \\
\hline$T_{\text {av }}$ & $\begin{array}{l}\text { average of breast and back skin } \\
\text { temperatures with a radiatio load }\end{array}$ & ${ }^{o} K$ \\
\hline$U$ & wind speed & $m \sec ^{-1}$ \\
\hline$\Delta X$ & average feather thickness & $\mathrm{cm}$ \\
\hline$\sigma$ & Stefan-Boltzman constant $8.132 \times 10^{-11} \mathrm{cal}$ & $\mathrm{cm}^{-2} \min ^{-1} \mathrm{o}_{\mathrm{K}}^{-4}$ \\
\hline$\xi$ & emissivity of bird surface $(\simeq 1.0)$ & dimensionless \\
\hline
\end{tabular}


Figure 1. Cylinder model of birds for heat trarisfer analysis. $M=$ metabolism; $E_{r}=$ respiratory heat loss; $Q_{\text {solar }}=$ all radiation incident on bird; $T_{r}=$ effective temperature of radiation source; $T_{a}=$ air temperature; $C_{f}=$ thermal conductance of feathers; $T_{f}=$ feather surface temperature; $T_{s}=$ skin temperature; $r_{j}=$ body radius; and $r_{0}=$ body + feather radius . 


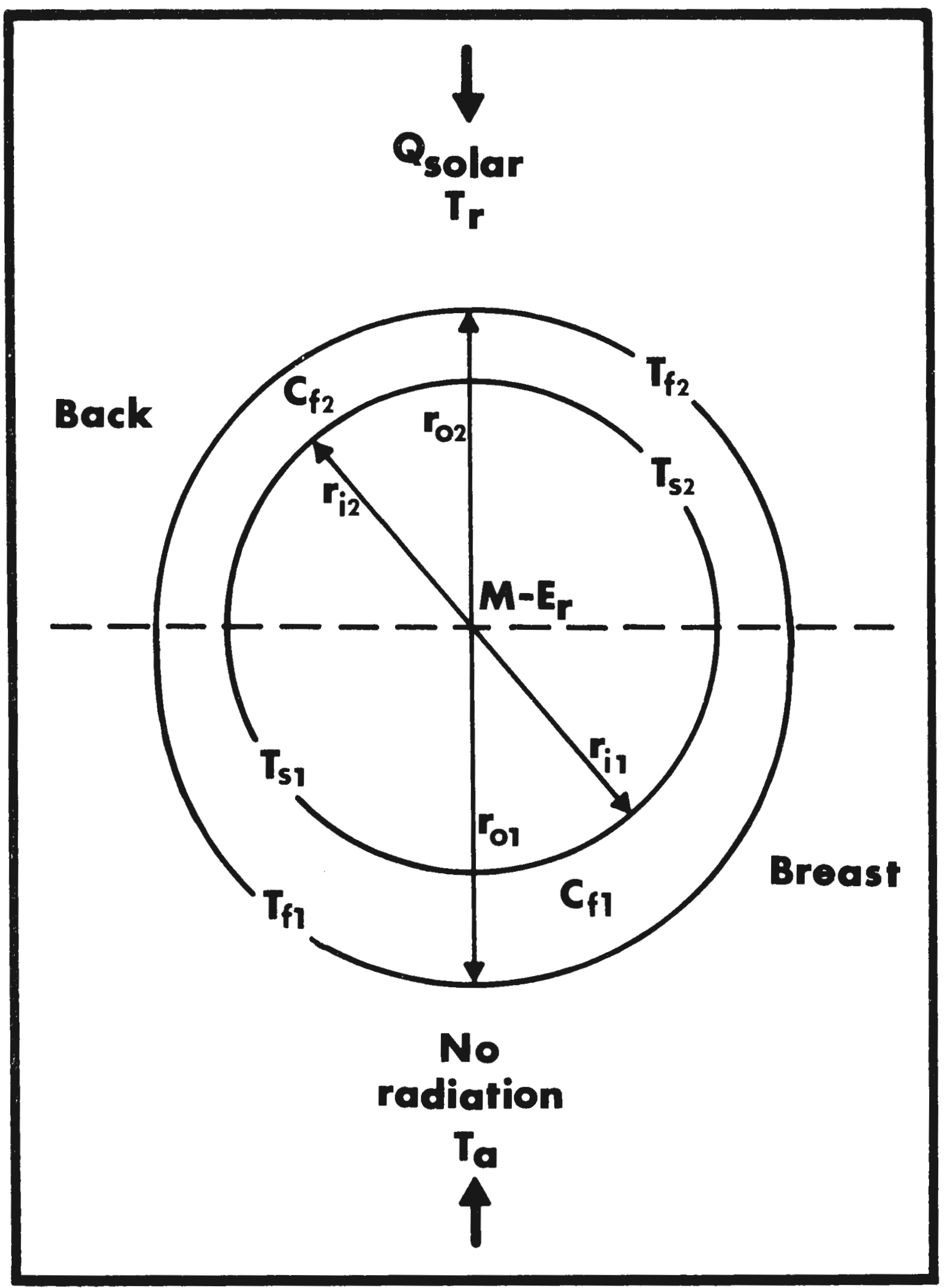




$$
M-E_{r}=K A \frac{\left(T_{S}-T_{f}\right)}{\Delta X}=C_{f}\left(T_{S}-T_{f}\right)
$$

So

$$
c_{f}=\frac{K A}{\Delta X},
$$

and $C_{f}$ has the units of $c a l \min ^{-1} O_{K^{-1}}$.

Before equations can be developed to predict metabolism, equations (A1) and (A2) must be solved for $C_{f}$, and the functional relationship of $C_{f}\left(C_{f}=f\left(U, Q_{s o l a r}, T_{a}\right)\right)$ must be determined. Since calculation of $C_{f_{r}}$ is dependent on assumption \#5 and the previous calculation of $\mathrm{C}_{f_{0}}$, data must be analyzed in pairs beginning with the zero radiation condition. Solution of equations (1) and (2) for $C_{f}$ would be a simple matter if all surfaces of the bird were at the same temperature and exposed to the same radiation environment. However, this is not the case, and several assumptions must be made to effect a solution:

1. With zero radiation load, breast and back skin temperatures are equal $\left(T_{S 1}=T_{S 2}\right)$.

2. With zero radiation load, breast and back surface temperatures are equal $\left(T_{f 1}=T_{f 2}\right)$.

3. With zero radiation load, apportionment of the total feather conductance between back and breast is based on feather thickness (breast feathers are thicker than back feathers) and respective surface areas.

4. The back receives all significant radiation.

5. Values for $C_{f l}, T_{S 1}$, and $T_{f l}$ are constant for all radiation loads incident on the back. 
Rearranging equation (2) and substituting zero radiation

parameters,

$C_{f_{0}} T_{S 1_{0}}-C_{f_{0}} T_{f l_{0}}=h_{c} A T_{f l_{0}}-h_{c} A T_{a}+\xi \sigma A F_{0}\left(T_{f l_{0}}^{4}-T_{a}^{4}\right)$.

Under zero radiation conditions, $Q_{a b s}$ is zero, and $F_{0}$ (view factor from the bird to the environment) equals 1.0. Linearizing the radiation terms,

$$
\begin{aligned}
& \xi \sigma F_{0}\left(T_{f l_{0}}^{2}-T_{a}^{2}\right)\left(T_{f l_{0}}^{2}+T_{a}^{2}\right) \\
& \xi \sigma F_{0}\left(T_{f l_{0}}-T_{a}\right)\left(T_{f l_{0}}+T_{a}\right)\left(T_{f 1_{0}}{ }^{2}+T_{a}^{2}\right),
\end{aligned}
$$

and letting

$$
h_{r}=\xi \sigma F_{0}\left(T_{f 1_{0}}+T_{a}\right)\left(T_{f 1_{0}}^{2}+T_{a}^{2}\right)
$$

then the net radiation exchange under zero radiation conditions is

$$
Q_{\text {rad }}=h_{r} A\left(T_{f 1_{0}}-T_{a}\right)
$$

The calculation of $h_{r}$ takes several forms that differ in the surface area term and/or the surface temperature used. $C_{f_{0}}$ is calculated with $h_{r}$, while $c_{f_{r}}$ is calculated with $h_{r l}$ and $h_{r 2}$.

$$
\begin{aligned}
& h_{r 1}=\xi \sigma F_{0}\left(T_{f]_{r}}+T_{a}\right)\left(T_{f 1_{r}}{ }^{2}+T_{a}^{2}\right) \\
& h_{r 2}=\xi \sigma F_{0}\left(T_{f 2_{r}}+T_{a}\right)\left(T_{f 2}{ }^{2}+T_{a}^{2}\right) .
\end{aligned}
$$

Under a radiation load the back of the bird "sees" a two part environment: the radiation source and all of the environment $\left(T_{a}\right)$ other than the radiation source. Since the absorbed radiation is considered on the left side of equation (2), the radiation heat transfer coefficient for the back with a radiation load $\left(h_{r 2}\right)$ considers only the long wave 
13

emissions from the bird. Rearranging equation (3).

$$
C_{f_{0}} \cdot T_{S 1_{0}}+h_{c} A T_{a}+h_{r} A T_{a}=C_{f} T_{f 1_{0}}+h_{c} A T_{f 1_{0}}+h_{r} A T_{f]_{0}}
$$

and solving for $\mathrm{T}_{\mathrm{fl}}$,

$$
T_{f T_{0}}=\frac{c_{f_{0}} T_{S I_{0}}+h_{c} A T_{a}+h_{r} A T_{a}}{c_{f_{0}}+h_{c} A+h_{r} A} .
$$

Isolating $\mathrm{T}_{\mathrm{S} 1_{0}}$ from equation (4),

$$
T_{f 1_{0}}={ }_{S I_{0}}^{T_{0}} \frac{c_{f_{0}}}{c_{f_{0}}+h_{c} A+h_{r} A} \frac{h_{c} A T_{a}+h_{r} A T_{a}}{c_{f_{0}}+h_{c} A+h_{r} A}
$$

Let

$$
z=h_{c} A T_{a}+h_{r} A T_{a} \text {, }
$$

and substitute equation (5) in equation (1),

$$
M-E_{r}=C_{f_{0}}{ }^{T_{S I}} \frac{\left(C_{f_{0}}+h_{c} A+h_{r} A\right)}{c_{f_{0}}+h_{c} A+h_{r} A}-{ }^{T_{S I_{0}}} \frac{c_{f_{0}}}{\frac{c_{f_{0}}+h_{c} A+h_{r} A}{c_{f_{0}}+h_{c} A+h_{r} A}} .
$$

Equation (1) becomes

$$
M-E_{r}=C_{f_{0}} \quad \frac{T_{S 1_{0}}\left(h_{C} A+h_{r} A\right)-z}{C_{f_{0}}+h_{C} A+h_{r} A} .
$$


Rearranging equation (6) to isolate $C_{f_{0}}$,

$\frac{M-E_{r}}{T_{S I_{0}}\left(h_{c} A+h_{r} A\right)-z}=\frac{c_{f_{0}}}{C_{f_{0}}+h_{c} A+h_{r} A}$

and letting

$$
y=\frac{M-E_{r}}{T_{S I_{0}}\left(h_{c} A+h_{r} A\right)-Z} \text {, }
$$

then

$$
c_{f_{0}}=\frac{Y\left(h_{c} A+h_{r} A\right)}{1-Y} .
$$

Energy lost with respiratory water $\left(E_{r}\right)$ was calculated as described by Calder and King (1974).

Calculation of $\mathrm{C}_{f_{r}}$ (total feather conductance with incident radiation) is dependent on assumption $\# 5$ and the calculation of $\mathrm{C}_{\mathrm{fl}}$.

$$
C_{f 1_{0}}=C_{f}(0.5) S_{1}
$$

where $S_{1}$ is a scale factor to apportion a larger percentage of the zero radiation feather conductance to the back (breast insulation is thicker than back insulation (refer to Appendix $C$ for computation of scale factor). With the breast feather conductance known, $C_{f 2}$ can be calculated by equation (8) which is a direct development of equation (6).

$$
M-E_{r}=\frac{{ }_{f 1_{r}}^{x_{1}}}{c_{f 1_{r}}+h_{c} A_{1}+h_{r 1} A_{1}}+\frac{{ }_{f 2} x_{2}}{c_{f 2}+h_{c} A_{2}+h_{r 2} A_{2}}
$$

where

$$
x_{1}=T_{S I_{r}}\left(h_{C} A_{1}+h_{r l} A_{1}\right)-z_{1}
$$




$$
\begin{aligned}
& x_{2}=T_{S 2}\left(h_{c} A_{2}+h_{r 2} A_{2}\right)-z_{2}, \\
& z_{1}=h_{c} A_{1} T_{a}+h_{r 1} A_{1} T_{a}, \text { and } \\
& z_{2}=Q_{a b s}+h_{c} A_{2} T_{a}+h_{r 2} A_{2} T_{a} .
\end{aligned}
$$

Let

$$
Y_{r}=M-E_{r}-\frac{c_{f 1_{r}} x_{1}}{c_{f 1_{r}}+h_{c} A_{1}+h_{r 1} A_{1}} .
$$

Then $\quad C_{f 2}=\frac{Y_{r}\left(h_{c} A_{2}+h_{r 2} A_{2}\right)}{x_{2}-Y_{r}}$

and

$$
c_{f_{r}}=c_{f 1_{r}}+c_{f 2} .
$$

Multiple regression analysis was used to develop the functional relationships of $C_{f}, T_{S}$, and $T_{f}$ with respect to air temperature, wind speed, and radiation. The equations are listed by species in Appendix $A$.

Calculation of a predicted metabolism value given the feather conductance relationship for the species is a relatively simple matter. Metabolism with zero radiation load is described by the equation

$$
M=C_{f_{0}} \frac{T_{S 1_{0}}\left(h_{c} A+h_{r} A\right)-z}{C_{f}+h_{c} A+h_{r} A}+E_{r} .
$$

Since the radiation environment is homogeneous with respect to all exposed animal surfaces with zero radiation load, the exclusive use of breast skin temperature and air temperature in equation (4) is reasonable. Under a radiation load, metabolism can be calculated using equation (5). 
16

$$
M=C_{f_{r}} \frac{T_{S_{a v}}\left(h_{c} A+h_{r_{a v}} A\right)-Z_{a v}}{C_{f_{r}}+h_{c} A+h_{r_{a v}} A}+E_{r}
$$

where

$$
h_{r_{a v}}=h_{r 1}+h_{r 2} \text { and } z_{a v}=z_{1}+z_{2}
$$


RESULTS

The combined effects of air temperature, wind and radiation

Least squares techniques were used to develop least square means and standard errors of the raw data and to surmarize the effects of radiation and wind on the weight specific metabolism (cal $\mathrm{hr}^{-1}$ body wt.-.75) of all birds (Fig. 2). Incremental increases in insolation produced iinear and parallel reductions in metabolism at all wind speeds, while wind produced non-linear increases in metabolism at all radiation loads. The greatest rates of metabolism change occurred at wind speeds less than $4.47 \mathrm{~m} \mathrm{sec}^{-1}$. Figure 3 illustrates the interactions among body size, radiation, and wind effects and their effect on weight relative metabolism (cal $\mathrm{g}^{-1} \mathrm{hr}^{-1}$ ). Least square means and standard errors are shown. Incremental increases in insolation again produced linear reductions in metabolism; the slope of the lines progressively decreased from kestrels $(115 \mathrm{~g})$ through red-tailed hawks $(1145 \mathrm{~g})$ and eagles $(4320 \mathrm{~g})$, a $1: 10: 40$ change in body size. Similar effects of wind on metabolism were also seen. Slope and non-linearity of response lines were greatest for kestrels, with progressive reductions in slope and the degree of non-linearity in red-tail and eagle data. Radiation and wind appear to have a greater impact on heat production in the smaller sized birds. This observation is supported by data (Fig. 4). Reduction of metabolism at all radiation loads was greatest for kestrels, with no significant differences in values between red-tails and eagles. Feather thickness is another measure of the degree of insulation from the environment. Average feather depth was $1.02 \mathrm{~cm}$ in the kestrels, $1.58 \mathrm{~cm}$ in red-tails, and $2.63 \mathrm{~cm}$ in eagles; a 1:1.5:2.5 relationship in insulation thickness. 


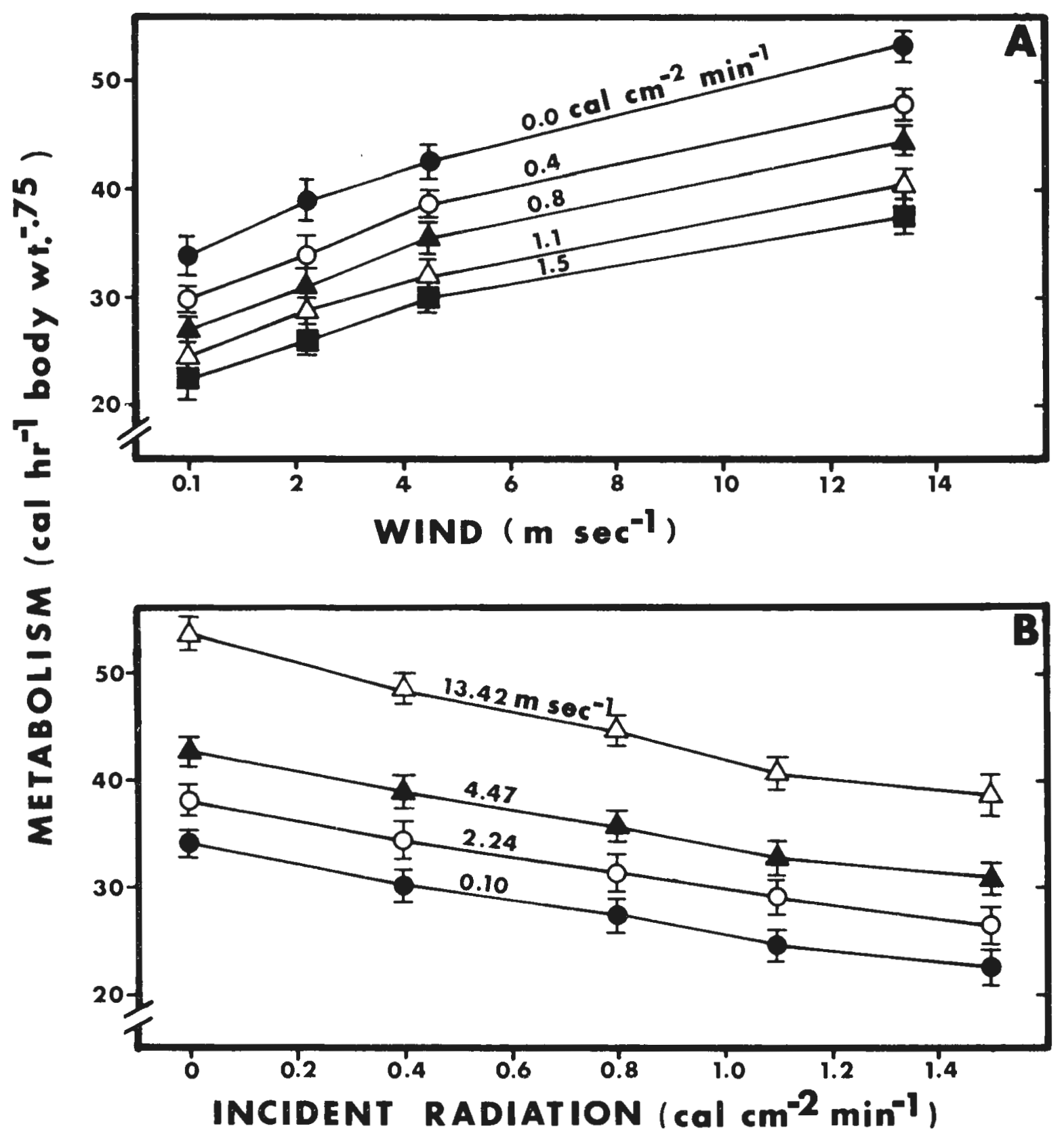

Figure 2. Least square means and standard errors summarizing for a 17 birds (A) the effect of wind on weight specific metabolism at five radiation loads and $(B)$ the effect of radiation on weight specific metabolism at four wind speeds 

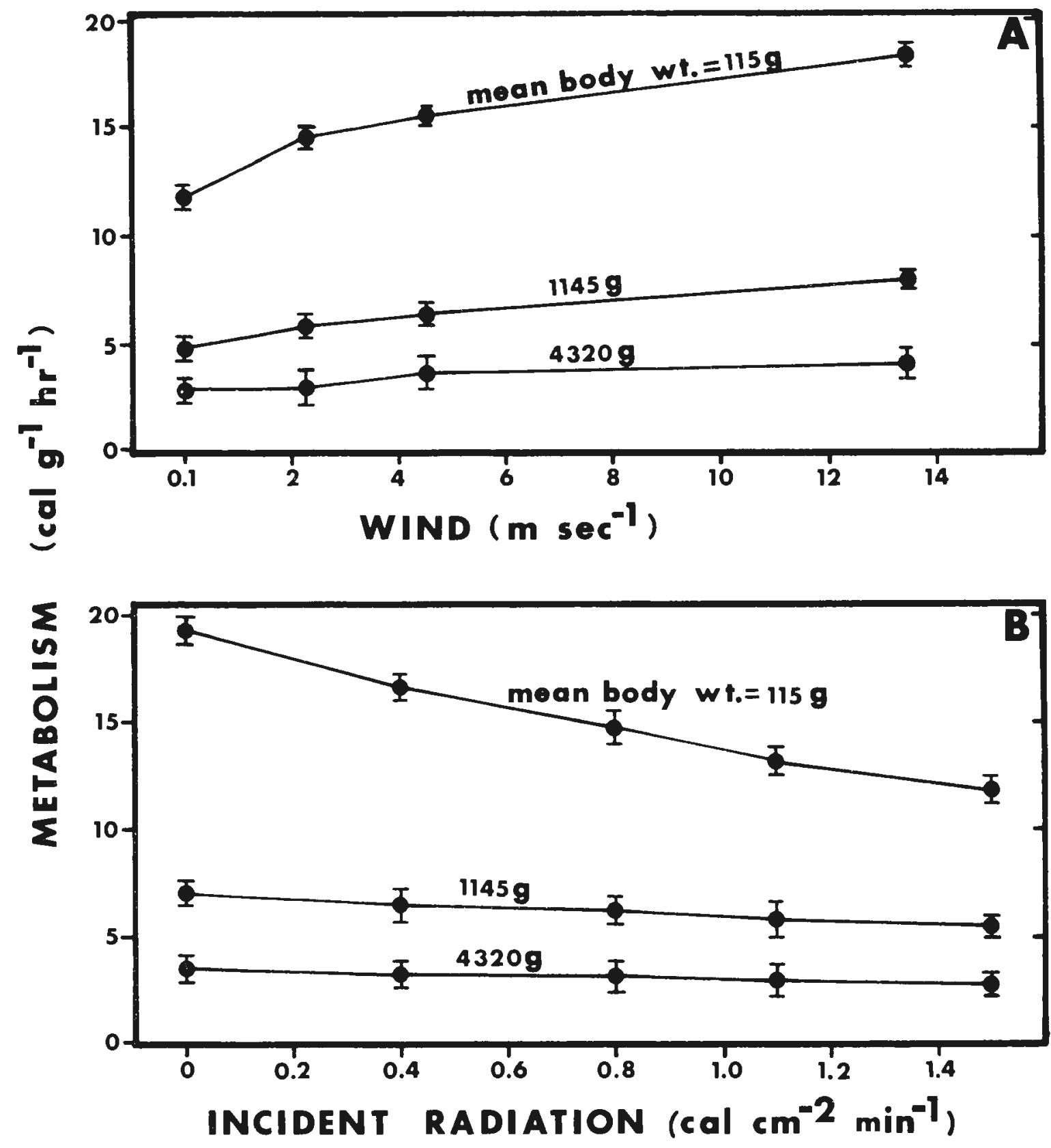

Figure 3. Least square means and standard errors summarizing $(A)$ the effect of wind and (B) the effect of radiation on the weight relative metabolism of the three classes of raptors. 
Figure 4. Least square means and standard errors summarizing the the metabolic reducing power of radiation on raptors. Since red-tail and eagle lines were not significantly different, the data for these two lines were combined. 


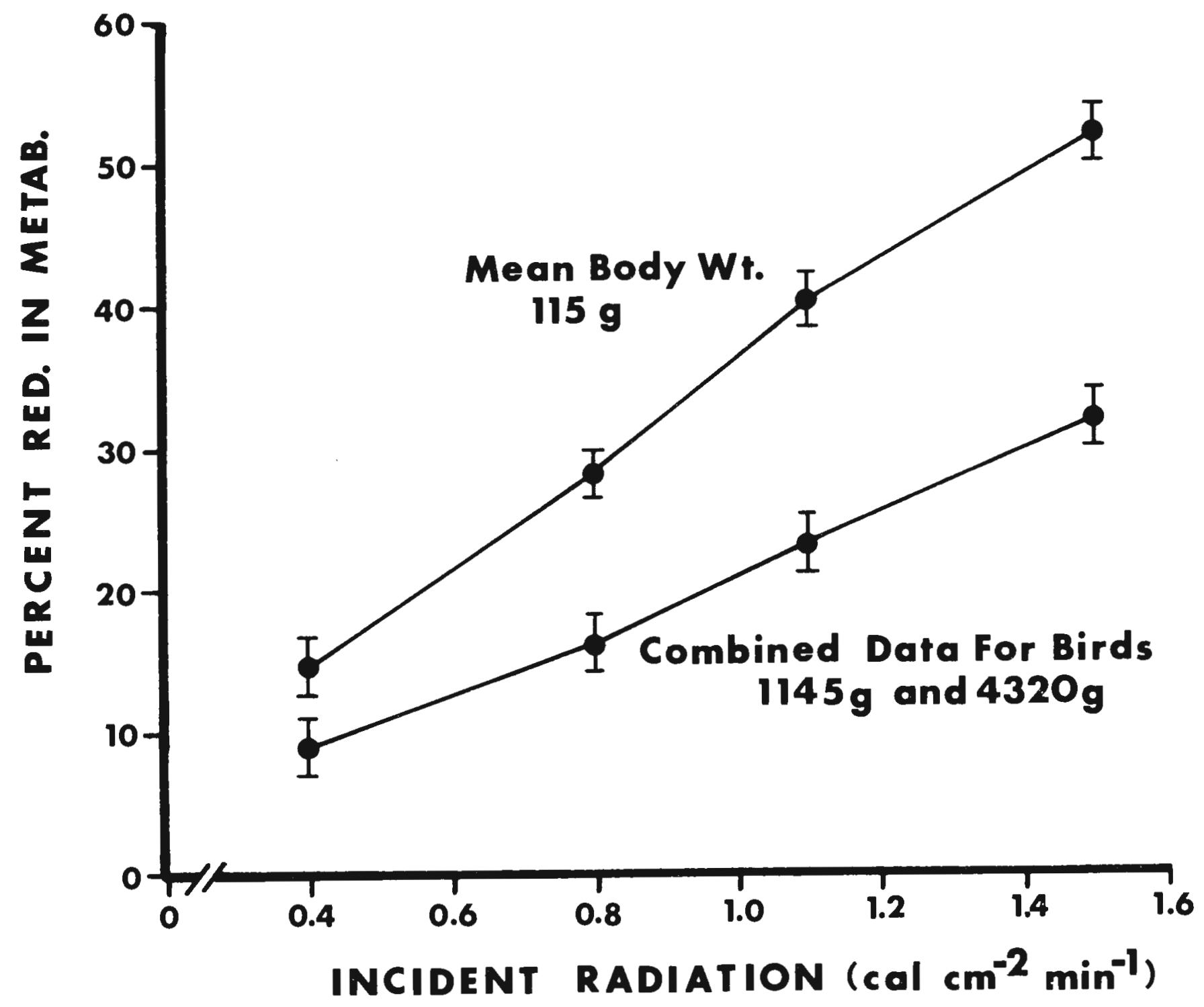


All birds began panting at ambient temperatures between 28 and $30 \mathrm{C}$ with radiation loads of $1.1 \mathrm{cal} \mathrm{cm}^{-2} \mathrm{~min}^{-1}$ or greater and zero wind. Although the birds were exhibiting active thermoregulation, panting was sufficient to maintain a stable body temperature at all ambient temperatures (to $+34 \mathrm{C}$ ). Under these environmental conditions, sharp rises in body temperature were recorded in all birds (particularly eagles) if any body movement occurred. Movement, probably representing escape behavior, normally appeared about 20 to 25 minutes after onset of exposure to these conditions. At this point, the birds were under positive thermal stress. Body temperature rose rapidly, apparentiy uncontrollably. In one instance, under zero wind, death resulted when the bird was not removed from the radiation load. Birds exposed to only slight wind (greater than $1.0 \mathrm{~m} \mathrm{sec}^{-1}$ ) did not exhibit thermal stress at any radiation load or air temperature used in the study.

Low ambient temperatures produced increases in metabolism that were accentuated by wind and moderated by radiation. Cold stress began in the kestrels at about $-5 \mathrm{C}$ and $13.47 \mathrm{~m} \mathrm{sec}^{-1}$ wind. Under these conditions, body temperature (normally 40.5 to $41.8 \mathrm{C}$ ) fell to levels less than $39 \mathrm{C}$ but stabilized with no radiation incident on the bird. At temperatures below $-10 \mathrm{C}, 4.47 \mathrm{~m} \mathrm{sec}^{-1}$ wind caused decreases in body temperature to approximately $36 \mathrm{C}$. Body movement ceased and metabolism increased to approximately 5.6 times basal. Only radiation loads of

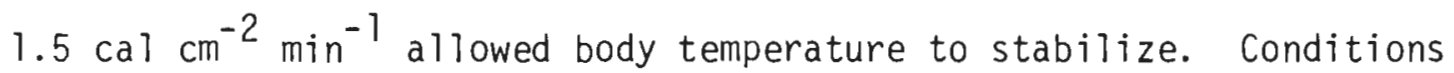
more severe than those described would have caused death in kestrels from hypothermia. Red-tailed hawks were not appreciably stressed during the most severe conditions of the study $(-17 \mathrm{C}$ air temperature, $13.42 \mathrm{~m} \mathrm{sec}^{-1}$ wind, and zero radiation). Under these conditions, body 
temperature fell an average of $1.5 \mathrm{C}$ but stabilized quickly, and metabolism increased to approximately 4.2 times basal which was probably less than the maximum resting metabolism (i.e.; summit metabolism of that individual). Summit metabolism has been reviewed by Hart (1971). Values ranged from 2.6 to 5.9 times basal rates for animals ranging in size from $10-2500 \mathrm{~g}$. Eagles exhibited no significant drop in body temperature at the most severe experimental conditions. Metabolism increased to approximately 3.5 times basal.

Figure 5 illustrates (1) the effect of air temperature on metabolism and (2) the reduction in metabolism due to maximum radiation loads, all under zero wind conditions. Least square regression lines were calculated for raw data and plotted with correlation coefficients. As air temperature decreased over the experimental range, metabolism increased approximately 2.7, 1.5, and 1.4 times for kestrels, red-tails, and eagles, respectively. A radiation load of $1.5 \mathrm{cal} \mathrm{cm}^{-2} \mathrm{~min}^{-1}$ reduced the rate of metabolism increase due to air temperature and caused an apparent decrease in the lower critical temperature for each species, thus extending the thermoneutral zone to lower air temperatures. Multiple regression analysis was used to develop predictive equations for metabolism, given average body mass, air temperature, wind speed, and radiation flux. The combined raptor model, used to predict metabolism over all species, had an $R^{2}$ value of 0.63 (Eq. 10). $M=14.6778-0.0025$ BDWT $-0.1725 \mathrm{~T}_{\mathrm{a}}-2.4044 \mathrm{Q}_{\text {Solar }}+0.9256 \mathrm{U}^{.5}$ where $M=$ weight relative metabolism $\left(\right.$ cal $\left.\mathrm{g}^{-1} \mathrm{hr}^{-1}\right)$, BDWT = average body mass $(g), T_{a}=$ air temperature $(C), Q_{\text {solar }}=$ radiation flux (cal $\left.\mathrm{cm}^{-2} \min ^{-1}\right)$, and $U=$ wind speed $\left(\mathrm{m} \mathrm{sec}^{-1}\right)$. Using the square root of wind as a predictor in equation (6) rather than wind, the overall 

Figure 5. Least square regression lines illustrating the change in metabolism due to radiation $(0.0$ and 1.5 cal $\mathrm{cm}^{-2} \min ^{-1}$ ) over the range of air temperatures $(-17$ to +34 C) for the three species of raptors. Extension of the thermoneutral zone and shift in lower critical temperature due to radiation and body size are also shown. 


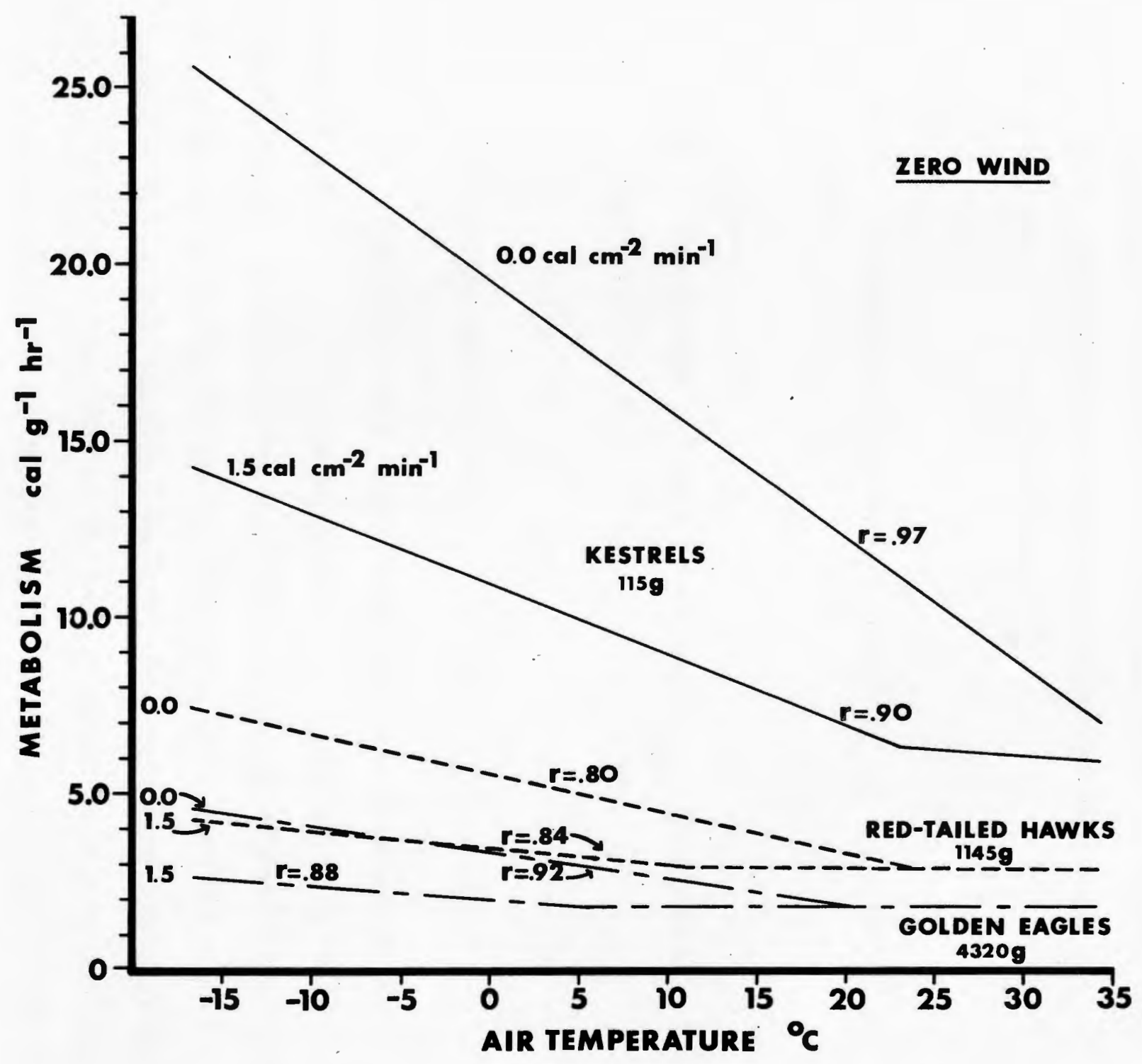


predictability was increased and a greater proportion of the total variance was explained. Analysis of variance indicated that no significant interactions between wind and radiation effects were present; however, strong interaction between body weight and wind and body weight and radiation was evident at the $P=0.99$ level. Separating the data by species increased the predictability of each separate model and reduced the amount of unexplained variance.

Kestrels:

$M=24.9926-0.0489$ BDWT $-0.3068 \mathrm{~T}_{\mathrm{a}}-4.7724 Q_{\text {solar }}+1.1688 \mathrm{U} .5$ $R^{2}=0.81$

Red-tailed hawks:

$M=13.2064-0.0059$ BDWT $-0.1467 T_{a}-1.0354 Q_{\text {solar }}+0.8822 U^{.5}$ $R^{2}=0.81$

Golden eagles:

$M=6.1168-0.0006$ BDWT $-0.0793 T_{a}-0.6665 Q_{\text {Solar }}+0.1284 U$

Wind, rather than the square root of wind, was used in equation ((13) based on the eagle curve (Fig. $3 A$ ) and as a result of analys is of polynomial fit for the data points. The square root of wind transformation mation described the kestrel data well, while wind was a good predictor for eagle metabolism. Red-tail data could have been described equally well with either wind or the square root of wind as a predictor. This observation, which may be tied to the degree of insulation from the environment, will be discussed later. 
Heat transfer analysis

Table 2 illustrates the degree of correlation between measured (actual) metabolism data, metabolism points predicted by the multiple regression equations and metabolism points predicted by the heat transfer analysis for body mass, air temperature, wind speed, and radiation values recorded during measurement of the actual metabolic data. Reduction of the correlation coefficient for kestrels in the Measured $X$ Biophysical category resulted from the inaccuracy of the biophysical model at ambient temperatures below $-5 \mathrm{C}$ and above $28 \mathrm{C}$. Because of the tight coupling of these small raptors to environmental conditions, body temperature was more labile under extreme environmental conditions than in the larger species, and the biophysical model was unable to predict changes in kestrel metabolism based only on feather conductance. In general, both models produced comparable predicted values; however, values predicted by the biophysical model more closely paralleled actual metabolism values. 
Table 2. Comparison of measured metabolism values with metabolism values predicted by the individual multiple regression equations and with the heat transfer analysis.

\section{Correlation Coefficients}

\begin{tabular}{lcc} 
Species & Measured X Regression & Measured X Biophysical \\
\hline $\begin{array}{l}\text { American } \\
\text { Kestrels }\end{array}$ & 0.90 & $0.91 *(0.68)$ \\
$\begin{array}{l}\text { Red-tailed } \\
\text { Hawks }\end{array}$ & 0.86 & 0.89 \\
$\begin{array}{l}\text { Golden } \\
\text { Eagles }\end{array}$ & 0.82 & 0.92 \\
\hline
\end{tabular}

*The correlation coefficient of 0.91 is applicable for data points for which $0.0 \mathrm{C} \leq \mathrm{Ta}>28.0 \mathrm{C}$. The correlation coefficient of 0.68 is applicable fór ali data points. 


\section{DISCUSSION}

\section{The combined effects of air temperature, wind, and radiation}

My data show that body size (graded variation in surface area to mass ratio) and the depth of feather insulation (associated with body size) play an integral role in the metabolic response of raptors to perturbations in the energy environment. The distinct separation of metabolism response curves (Figs. 3, 4, and 5) appears to be primarily a function of body size. The smaller the bird, the larger the surface area to mass ratio. Since heat loss is a function of surface area, and heat production is a function of mass, metabolism must be more intense as body size becomes smaller. While body size and metabolic intensity determine curve separation, the shape of each curve and the rate of metabolism change (slope) due to environmental variables appears to be a function of feather depth and of the likelihood of wind and radiation reaching the skin surface. Brody (1945) found that plumage weight was approximately a linear function of body weight in domestic fowl and that large birds had proportionately more plumage per unit surface area than small birds. the average feather depth for kestrels, red-tails, and eagles $(1.02 \mathrm{~cm} 1.58 \mathrm{~cm}$, and $2.63 \mathrm{~cm}$, respectively) should be reflected in intensity of response to environmental conditions. However, the intensity of of metabolic response to environmental conditions undoubtedly varies seasonally as a function of feather quality and thickness ( in addition to seasonal biochemical acclimatization). In a review of the literature, Calder and King (1974) report seasonal variations in plumage weight of 25-75 percent in wild and captive birds. Although the values that I measured appeared to be average for my birds which were held 
indoors in captivity, the quality and thickness of the plumage may not have been indicative of the wild population from which they were taken.

An explanation of the differences in curve shape and slope comes from flow mechanics and boundary layer theory. The body feather coat and associated trapped air can be viewed as a "super stable" boundary layer with the feather elements impeding convective currents. With no wind penetration of the feather elements, heat transfer from the skin is relatively slow and limited to natural convection, conduction, and net radiation exchange through the feathers. Above penetration velocity (the velocity that significantly increases heat transfer in the feathers), the air flow is penetrating the feather layer and enhancing the air conduction mechanisms by turbulent mixing, thus reducing the boundary layer thickness and modifying the apparent thermal conductivity within the feathers and the convection coefficient at the feather-air interface (Warren Porter, pers. comm.).

Wind may have penetrated the feathers of my birds and modified their skin environment depending on the total feather thickness of each species. The degree of non-linearity of the metabolism versus wind lines (Fig. 3 A ) may indicate that wind penetration to the skin occurs in kestrels, since heat transfer from bare cylinders is similar to that observed in the kestrels. Kelty and Lustick (1977) reported non-linear increases in metabolism as a function of wind speed $\left(4.2 \mathrm{~m} \mathrm{sec}^{-1}\right)$ and air temperature $(-10 \mathrm{C})$ for starlings. They suggested wind penetration of the feathers as a possible explanation. Since the eagle curve is linear, eagle skin probably does not "see" the wind directly but experiences only an apparent reduction in feather thickness and insulation. Metabolic 
response of red-tails to wind is intermediate between kestrels and eagles but nearly linear. Absorption of radiation moderates the effect of wind by increasing the effective temperature of the skin. The amounts of radiant energy reaching the skin is dependent on feather thickness and the wind speed. Radiation tends to project the birds into a thermoneutral condition at reduced air temperatures.

The effect of wind on boundary layer conditions becomes increasingly important as a passive thermoregulatory mechanisms at ambient temperatures approaching core temperature, particularly for avian raptors that are exposed to incidnet radiaiton for prolonged periods. I observed that wind speeds greater than about $1.0 \mathrm{~m} \mathrm{sec}^{-1}$ were sufficient to maintain thermal balance in the three raptor species at temperatures to $+34 \mathrm{C}$ whereas the body temperature rose at $+34 \mathrm{C}$ with radiation

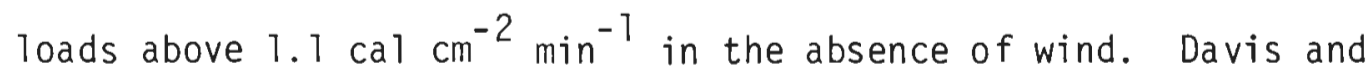
Birkebak $(1974,1975)$ have shown that the penetration velocity in fur is less than .06 $\mathrm{M} \mathrm{sec}^{-1}$, and its value depnds on fur fiber diameter and density, and fur depth and orientation relative to the flow direction. Because of feather construction, this value may be somewhat greater in birds than mammals. My data indicate that avian raptors maintain a constant body temperature at air temperatures near core temperature even with maximum solar raidation loads by panting and exposure to convective processes.

There are several interesting ecological implications of the graded variations in cold stress observed at temperatures below $0 \mathrm{C}$ in my birds. The difficulty of maintaing thermal balance in birds during roosting and activity in cold weather is tied to body size and the degree of insulation afforded by the feather coat. During cold weather, only two 
possibilities exist for reduction of net heat loss outside the realm of physical thermoregulation. First, physical shelter may reduce (1) heat loss due to convection, (2) the thermal gradient from core to environment, and (3) emissive radiation loss from the bird. Small raptors such as kestrels regularly roost in cavities, barns, or other shelters during the winter season. The kestrel's thermal relationship with the winter environment necessitates protection from strong winds and extremely cold temperatures, particularly at night. Kendeigh (1961) found that house sparrows inhabiting nest boxes during the winter conserved $4.9,11.1$, and 12.6 percent of their daily resting energy requirement at air temperatures (outside the box) of $+17 \mathrm{C},-8 \mathrm{C}$, and $-20 \mathrm{C}$, respectively. If kestrels are similar in their energy conserving capabilities, they significantly reduce their energy requirements (possibly by 10 percent) by utilizing protected roosts during severe winter conditions. Bent (1961) cites records of kestrels wintering in large cities and roosting in niches of high office buildings. Enderson (1960) reported an inverse relationship between wind in combination with low temperatures and kestrel activity. He also noted kestrels roosting in tree cavities and buildings. Mills (1975) noted sudden and significant decreases in kestrel population density during periods of severe cold and snow in central Ohio. He hypothesized that the winter existence of kestrels during severe weather in Ohio is marginal and that the lack of protected roost sites limits the population. This hypothesis can probably be applied to kestrels with more certainty along the northern limit of their winter range which extends to $49^{\circ}$ north latitude in North America (synthesis of Christmas Bird Count data, 1970-1976, American Bird). Keith Bildstein (unpubl. data, Ohio State Univ.) has regularly observed 
kestrels hunting directly from a protected roost area during severe winter conditions. Their flight activity was at a minimum, and their food intake shifted from primarily small mammals to small birds inhabiting the immediate area around the roosts. Second, passive or active (sunbathing) utilization of radiation reduces the net heat loss from the bird. Morton (1967) reported that irradiated $\left(1.0 \mathrm{cal} \mathrm{\textrm {cm } ^ { - 2 }}\right.$ $\min ^{-1}$ ) white-crowned sparrows conserved as much as $4.1 \mathrm{Kcal}$ during a five hour period at an air temperature of $7 \mathrm{C}$ when compared to nonirradiated controls. Bildstein (pers. comm.) observed that kestrels, and small raptors in general, were more active at cold air temperatures on clear days than on cloudy days, implying that energy is conserved with incident solar radiation. Solar radiation is clearly a significant factor in the energy economy of birds. In general, the values for reduction of metabolic output due to radiation that $I$ recorded for kestrels, red-tails, and eagles were less than those reported for zebra finches (Hamilton and Heppner, 1967, [23 percent at $\left.1.23 \mathrm{cal} \mathrm{cm}^{-2} \mathrm{~min}^{-1}\right]$ ), white-crowned sparrows (De Jong, 1976, [44 percent at $1.5 \mathrm{cal} \mathrm{cm}^{-2} \mathrm{~min}^{-1}$ ]), and roadrunners (Ohmart and Lasiewski, 1971; 441 percent at $0.8 \mathrm{cal} \mathrm{\textrm {cm } ^ { - 2 }}$ $\left.\left.\min ^{-1}\right]\right)$. The discrepencies appear to be the result of a more complex thermal environment in my study. In the past, combined effects of air temperature, wind and radiation have not been applied to birds. Previous work has been done entirely in metabolism chambers which significantiy affect heat transfer from animals (Porter, 1969). The wind tunnel that I used more closely simulated the natural thermal environment than have metabolism chámbers. As an example, my data from red-tails and kestrels can be used to illustrate the impact of solar radiation on raptor energy expenditure: 
1 January

Logan, Utah

Red-tails: (average body weight $=1145 \mathrm{~g}$ )

Zero wind

Radiation load
(0.0 cal $\left.\mathrm{cm}^{-2} \mathrm{~min}^{-1}\right)$

Air temperature $=-20 \mathrm{C}$

Metabolism from equation (12)
Zero wind

Radiation load

$\left(0.741 \mathrm{cal} \mathrm{cm}^{-2} \mathrm{~min}^{-1}\right)$

Air temperature $=-20 \mathrm{C}$

Metabolism from equation

(8.64 cal $\mathrm{g}^{-1} \mathrm{hr}^{-1}$ )

$$
\text { (9.38 } \left.\mathrm{cal} \mathrm{g}^{-1} \mathrm{hr}^{-1}\right)
$$

Metabolism reduction due to radiation $=8.0$ percent

$=0.74 \mathrm{cal} \mathrm{\textrm {g } ^ { - 1 }} \mathrm{hr}^{-1}$

$=0.85 \mathrm{Kcal} \mathrm{hr}^{-1}$ for a $1145 \mathrm{~g}$ bird

Kestrels: (average body weight $=115 \mathrm{~g}$ )

\section{Zero wind}

Radiation load
$\left(0.0 \mathrm{cal} \mathrm{cm}^{-2} \mathrm{~min}^{-1}\right)$

Air temperature $=-20 \mathrm{C}$

Metabolism from equation (11)

$\left(25.51 \mathrm{cal} \mathrm{g}^{-1} \mathrm{hr}^{-1}\right)$
Zero wind

Radiation load

$\left(0.741 \mathrm{cal} \mathrm{cm}^{-2} \min ^{-1}\right)$

Air temperature $=-20 \mathrm{C}$

Metabolism from equation (11)

(22.10 $\left.\mathrm{cal} \mathrm{g}^{-1} \mathrm{hr}^{-1}\right)$

Metabolism reduction due to radiation $=13.4$ percent

$$
\begin{aligned}
& =3.41 \mathrm{cal} \mathrm{g}^{-1} \mathrm{hr}^{-1} \\
& =0.39 \mathrm{Kcal} \mathrm{hr}^{-1} \text { for a } 115 \mathrm{~g} \text { bird }
\end{aligned}
$$

Generalizing from Kendeigh's nest box work and considering the prediction of energy conserved by radiation, kestrels may be able to conserve as much as 15 percent of their daily resting energy requirement by restricting their daily activity during severe winter conditions.

Recent wind tunnel data on American kestrels (James A. Gessaman, pers. comm.) show strong correlations between air temperature and core temperature during flight and between air temperature and duration of flight. Body temperature decreased during flight at all air temperatures below $5 \mathrm{C}$. Body temperature dropped an average of $0.65 \mathrm{Cmin}^{-1}$ 
and $0.1 \mathrm{Cmin}^{-1}$ at -10 and 0 air temperatures, respectively. Post $\mathrm{fl}$ ight body temperatures were as low as $37 \mathrm{C}$. The duration of flight was also inversely correlated with air temperatures below $5 \mathrm{C}$. The birds terminated flight at air temperatures below $-10 \mathrm{C}$ by 1 anding on the wind tunnel floor and crouching low near the floor. In this condition, the birds were fluffed up and would not resume flying even when picked up and tossed into the wind, repeatedly. Raptor migration data collected by Stephen Hoffman and Wayne Potts (unpubl. data, Utah State Uinv.) indicate that flight activity of small falcons and accipiters may be greatly affected by air temperature. These raptors were not observed migrating until air temperatures along the flight path rose to approximately $+5 \mathrm{C}$, while buteos and eagles began daily migration flights at all air temperatures recorded (to about -10 C). The above examples illustrate (1) the significant effect of the thermal environment on the activity budget of the raptor in the field and (2) that a small raptor is more tightly coupled to its thermal environment than a large raptor.

At the outset of this study, my purpose was to develop a set of simple equations to predict resting metabolism of avian raptors ranging in size from small falcons to eagles as a function of average body mass, air temperature, wind speed, and radiation load. The predictability of the combined raptor model (Eq. 6) is relatively low, but it is useful for estimating resting metabolism for raptors not examined in this study. The large range of body size appears to account for the difference between the combined raptor model and the three models of the individual species with respect to the level of predictability and the amount of variance explained by the model parameters. Additional variance can be 
explained by interaction between body weight and wind and body weight and body weight and radiation. However, deriving meaningful values for these interactions and using the values in prediction equations is impossible. The appropriate individual species models should be used when estimating resting metabolism of kestrels, red-tails, and eagles. Use of the combined raptor model should be limited to species not examined during this study. Caution should also be used in applying the kestrel model (equation 7 ) at air temperatures below $-5 \mathrm{C}$ in the presence of wind. The model appears to have excellent predictability at temperatures above $-5 \mathrm{C}$ and all wind speeds used during the study. However, predicted metabolism values for air temperatures below $-5 \mathrm{C}$ are consistently lower than measured avlues when wind is incident on the bird. The discrepancy may be involved with the decreases in body temperature that accompany summit metabolisms. This could be a fruitful area for new research. Red-tails and eagle models give valid estimates of metabolism over the irange of air temperatures and wind speeds examined during this study. The following guide to roughly estimating the lowest combination of cold weather conditions under which a red-tailed hawk could maintain thermal balance is an example of one use of the multiple regression models that I have presented:

Red-tailed hawk: (average body weight $=1145 \mathrm{~g}$ )

1) Predict standard metabolic rate from Aschoff and Poh1 (1970):

$$
\begin{aligned}
M=a W^{b}, \text { where } & a=91.0 \\
b & =0.729 \\
& W=\text { body weight }(\mathrm{Kg}) \\
M=4.18 \mathrm{kcal} \mathrm{hr}^{-1} &
\end{aligned}
$$


2) Assume a summit metabolism for the species:

For my purpose, I will assume a value 5 times the standard metabolic rate.

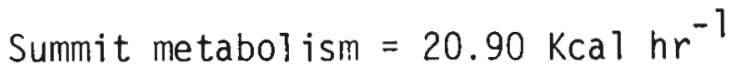

3) Set the parameters of equation (8) at the desired values:

$$
\begin{aligned}
Q_{\text {solar }} & =0.0 \mathrm{cal} \mathrm{cm}^{-2} \mathrm{~min}^{-1} \\
U & =13.47 \mathrm{~m} \mathrm{sec}^{-1} \\
\text { BDWT } & =1145 \mathrm{G} \text { (average) } \\
M & =18.28 \mathrm{cal} \mathrm{g} \mathrm{gr}^{-1}(20.90 \mathrm{Kcal} \mathrm{hr} * 1000 / 1145 \mathrm{~g})
\end{aligned}
$$

4) Solve equation (8) for air temperature:

$$
T_{\mathrm{a}}=-58.6 \mathrm{C}
$$

This air temperature value represents the approximate temperature at which the average re-tail should be metabolizing at a maximal rate while at rest in a strong wind with no radiation load.

I estimated a summit metabolism value of 5 times the standard metabolic rate. This value is reasonable when considering the range of summit metabolisms represented in the literature and the value of 5.6 times standard metabolic rate measured for kestrels in this study. Summit metabolism, as I have used the term, refers to the maximal oxidative metabolism that can be sustained while the bird is at rest. There is no maintenance provision in the definition, and the maximal rate of oxidative metabolism is reached only after hypothermia is experienced by the animal (Precht, 1973). The Aschoff and Pohl equation also appears to be a reasonable estimate of standard metabolic rates for raptors. I measured standard metabolism values of $0.889 \mathrm{Kcal} \mathrm{hr}^{-1}$ (kestrels), $3.510 \mathrm{Kcal} \mathrm{hr}^{-1}$ (red-tailed hawks), and $9.483 \mathrm{Kcal} \mathrm{hr}^{-1}$ (golden eagles) compared to values of $0.784,4.185$, and $11.018 \mathrm{Kcal}$ $\mathrm{hr}^{-1}$, respectively, predicted by the Aschoff and Pohl equation. 
Heat transfer analysis

The usefulness of heat transfer analysis and the development of biophysical models describing the energy interaction of animals with their environments has been discussed by several investigators. In their preface to Perspectives of Biophysical Ecology, Gates and Schmerl (1975) state, "The purpose of a theoretical model is to use it to explain observed facts and to make predictions beyond the realm of observation." Bakken and Gates (1975) feel that mathematical modeling studies in science are not an end in themselves, but rather a tool. "The fundamental purpose of mathematical analysis is to provide generalized, intellectually tractable insight into the operation and interaction of the complex factors involved in the physical and biological process under study." Perhaps the most evciting reason for using modeling techniques to examine biological processes is the large amount of complexity that can be built into a theoretical model. To obtain a comparable degree of complexity in lab or field experiments is often prohibitive in terms of cost and time. Although the aspect of complexity in theoretical modeling is an asset to biological analysis, complexity has historically stifled rigorous validation experiments with biological systems.

Until recently, validation of biophysical models for homeotherms other than man has been lacking. Robinson (1976) showed that a heat transfer model based on the internal and external resistances (in the form of electrical circuit analogs) to heat flow in whitecrowned sparrows produced estimates of metabolic rate under air temperature-wind regimes to within 10 percent of measured values. Mahoney and King (1977) have validated a heat transfer model based on equivalent environmental 
temperature with laboratory data from metabolism chambers. They state that the black-body equivalent temperature model predicts metabolic rate or white-crowned sparrows in simple laboratory environments with an algebraic error of -1.1 percent. However, it is not clear how this value was determined. The rather simple model that has been developed in this study describes the heat transfer from avian raptors reasonable well, and it represents an attempt to evaluate the accuracy of the model by comparison to statistical analysis and modeling. The simplicity of the model results from the use of feather thermal conductance which alleviates the problem of understanding the details of energy transfer through the feathers (e.g. temperature profiles and turbulent mixing rates). Although the model can theoretically be applied to all birds, skin temperatures and feather surface temperatures must be known for various air temperature wind, and radiation combinations. Metabolism must also be known before the functional relationship of feather thermal conductance can be determined $\left(C_{f}=f\left(T_{a}, U, Q_{\text {solar }}\right)\right.$. Technically, the model applies only to American kestrels, red-tailed hawks, and golden eagles. The model predicts metabolic heat production more accurately than multiple regression analysis, a common analytical technique of the biological sciences.

In summary, heat transfer analysis and biophysical modeling appear to be viable techniques for accurately describing energy interactions between raptors and their environments. These techniques may be more reliable than contemporary statistical approaches to biological analysis. 
CONCLUSIONS

Radiation loads reduced resting metabolism of raptors at all wind speeds and projected the raptors into a thermal neutral condition at a decreased lower critical temperature. At air temperatures above thermal neutrality and in the absence of wind, radiation levels above

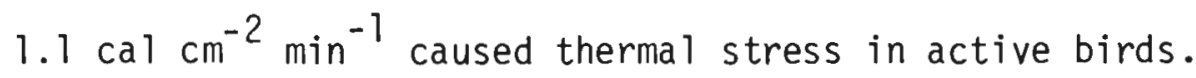

The effects of wind on metabolism were tightly coupled to body size and the thickness of the feather coat. Wind caused non-linear increases in kestrel metabolism as a result of wind penetration of the feather coat and exposure of the skin to forced convection processes. In red-tailed hawks, wind produced slightly non-linear increases in metabolism, suggesting that wind penetration to the skin occurred only at higher wind velocities. Changes in metabolism of golden eagles due to wind were linear.

Combinations of cold environmental temperatures and wind caused summit metabolisms in kestrels. Kestrels became cold stressed at air temperatures below $-5 \mathrm{C}$ with winds greater than $4.47 \mathrm{~m} \mathrm{sec}^{-1}$. My observations and other recent data suggest that kestrels begin reducing their activity at ambient temperatures below 0 to $5 \mathrm{C}$. Activity of red-tailed hawks and other large buteos and eagles is less noticeably affected by cold weather conditions.

Multiple regression models which predict resting metabolic rate of specific raptor species as a function of body mass, air temperature, wind speed, and radiation load produce reasonable estimates of metabolic rate. However, the combined raptor model (Eq. 11) is less reliable and should be used only for species not examined in this study. The 
very large range in body size appears to be responsible for the reduction in reliability of the full model.

Theoretical modeling of the heat transfer from raptors, in terms of an energy environment, was a valid means of estimating levels of metabolic heat production. These techniques may be more reliable than some contemporary statistical approaches to biological analysis. 


\section{LITERATURE CITED}

Aschoff, J. and H. Pohl. 1970. Rhythmic variations in energy metabolism. Fed. Proc., Fed. Amer. Soc. Exp. Biol. 29:1541-1552.

Bakken, G.S. 1976. A heat transfer analysis of animals: Unifying concepts and the application of metabolism chamber data to field ecology. J. Theor. Biol. 60:337-384.

Bakken, G.S. and D.M. Gates. 1975. Heat transfer analysis of animals: Some implications for field ecology, physiology, and evolution, pp. 225-290. In D.M. Gates and R.B. Schmerl (Eds.). Perspectives of bicphysical ecology. Springer-Verlag, New York. pp. 609.

Bartlett, P.N. and D.M. Gates. 1967. The energy budget of a lizard on a tree trunk. Ecology 48:315-322.

Bent, A.C. 1961. Life histories of North American birds of prey. Dover Publ., New York. pp. 482.

Birkebak, R.C. 1966. Heat transfer in biological systems. Int. Rev. Gen. Exp. Zool. 2:269-344.

Birkebak, R.C. and C.J. Cremers. 1965. Thermal modeling applied to animal systems. Paper presented at winter meetings of the American Society of Mechanical Engineers (November 1965).

Brody, S. 1945. Bioenergetics and growth. Von Nostrand-Reinhold, Princeton, New Jersey. pp. 1023.

Calder, W.A. and J.R. King. 1974. Thermal and caloric relations of birds, pp. 259-413. In D.S. Farner and J.R. King (Eds.). Avian biology vol. IV. Academic Press. pp. 504.

Davis, L.B. and R.C. Birkebak. 1974. On the transfer of energy in layers of fur. Biophys. J. 14:249-268.

Davis, L.B. and R.C. Birkebak. 1975. Convective energy transfer in fur, pp. 525-548. In D.M. Gates and R.B. Schmerl (Eds.). Perspectives of biophysical ecology. Springer-Verlag, New York. pp. 609.

De Jong. A.A. 1976. The influence of simulated solar radiation on the metabolic rate of White-crowned sparrows. Condor 78:174-179.

Depocas, F. and J.S. Hart. 1957. Use of the Pauling oxygen analyzer for measurement of oxygen consumption in animals in open-circuit systems and in a short-lag, closed-circuit apparatus. J. Appl. Physiol. 10:388-392.

Enderson, J.H. 1960. A population study of the sparrow hawk in eastcentral Illinois. Wilson Bull. 72:222-230. 
Gates, D.M. 1962. Energy exchange in the biosphere. Harper and Row, New York. pp. 151.

Gates, D.M. and R.B. Schmerl. 1975. (Eds.). Perspectives of biophysical ecology. Springer-Verlag, New York. pp. 609.

Gessaman, J.A. 1972. Bioenergetics of the Snowy Ow1, Nyctea scandiaca. Arctic Alp. Res. 4:223-238.

Hamilton, W.J., III and F. Heppner. 1967. Black pegmentation: Adaptation for concealment or heat conservation. Science 158: $1340-1341$.

Hart, U.S. 1971. Rodents, pp. 1-749. In G.C. Whittow (Eds.). Comparative physiology of thermoregulation, vol. II, Mammals. Academic Press. pp. 410.

Heller, H.C. 1972. Measurements of convective and radiative heat transfer in small mammals. J. Mammal. 53:289-295.

Heppner, F. 1970. The metabolic significance of differential absorption of radiant energy by black and white birds. Condor 72:50-59.

Kelty, M.P. and S.I. Lustick. 1977. Energetics of the starling (Sturnus vulgaris) in a pine woods.

Kendeigh, S.C. 1961. Energy of birds conserved while roosting in cavities. Wilson Bul1. 73:140-147.

King, J.R. 1964. Oxygen consumption and body temperature in relation to ambient temperature in the White-crowned sparrow. Comp. Biochem. Physiol. 12:13-24.

Lustick, S. 1969. Bird energetics: Effects of artificial radiation. Science 163:387-390.

Mahoney, S.A. and J.R. King. 1977. The use of the equivalent blackbody temperature in the thermal energetics of small birds. J. Thermal Biol. 2:115-120.

Mills, G.S. 1975. A winter population study of the american kestrel in central Ohio. Wilson Bul1. 87:241-247.

Morton, M.L. 1967. The effects of insolation on the diurnal feeding patterns of white-crowned sparrows (Zonotrichia leucophrys gambelii). Ecology 48:690-694.

Ohmart, R.D. and R.C. Lasiewski. 1971. Roadrunners: Energy conservation by hypothermia and absorption of sunlight. Science 172:67-69. 
Porter, W.P. 1969. Thermal radiation in metabolic chambers. Science $166: 115-117$.

Porter, W.P. and D.M. Gates. 1969. Thermodynamic equilibria of animals with environment. Ecol. Monogr. 39:245-270.

Precht, H., J. Christophersen, H. Hensel, and W. Larcher. 1973. Temperature and $1 \mathrm{ife}$. Springer-Verlag, New York. pp. 779.

Robinson, D.E., G.S. Campbell, and J.R. King. 1976. An evaluation of heat exchange in small birds. J. Comp. Physiol. 105:153-166.

Spotila, J.R., 0.H. Soule, and D.M. Gates. 1972. The biophysical ecology of the alligator: Heat energy budgets and climate spaces. Ecology 53:1094-1102. 
APPENDICES 


\section{Appendix A}

Functional relationships of respiratory water loss, feather thermal conductance, skin temperature, and feather surface temperature are listed by species. NOTE: The units of $E_{r}$ in the following equations are cal $\mathrm{gm}^{-1}$ $h r^{-1}$.

American Kestrels:

$$
\begin{aligned}
& E_{r}=1.1633+\left(0.047 \mathrm{~T}_{a}\right)+(0.0637 \mathrm{U})-\left(0.6793 \mathrm{Q}_{\text {solar }}\right) \\
& C_{f}=2.4048+\left(0.0347 \mathrm{~T}_{\mathrm{a}}\right)+(0.2295 \mathrm{U})-\left(1.2978 \mathrm{Q}_{\text {solar }}\right) \\
& T_{S 1}=14.6458+\left(0.681 \mathrm{~T}_{a}\right)-(0.4199 \mathrm{U})+\left(0.1937 \mathrm{E}-10 \mathrm{Q}_{\text {sol ar }}\right) \\
& T_{S 2}=17.1156+\left(0.5802 \mathrm{~T}_{a}\right)-(0.5798 \mathrm{U})+\left(4.4544 \mathrm{Q}_{\text {sol ar }}\right) \\
& T_{f 1}=12.1417+\left(0.7247 \mathrm{~T}_{\mathrm{a}}\right)-(0.4354 \mathrm{U})+\left(2.1614 \mathrm{Q}_{\text {solar }}\right) \\
& T_{f 2}=12.6225+\left(0.8168 \mathrm{~T}_{\mathrm{a}}\right)-(0.821 \mathrm{U})+\left(9.6526 \mathrm{Q}_{\text {sol ar }}\right)
\end{aligned}
$$

Red-tailed Hawks:

$$
\begin{aligned}
& E_{r}=0.3503+\left(0.0118 T_{a}\right)+(0.0251 U)-\left(0.0964 Q_{\text {solar }}\right) \\
& C_{f}=5.3985+\left(0.0286 T_{a}\right)+(0.6432 U)-\left(1.7024 Q_{\text {solar }}\right) \\
& T_{S 1}=19.896+\left(0.6062 T_{a}\right)-(0.4109 U)-\left(0.1095 Q_{S o l a r}\right) \\
& T_{S 2}=22.6209+\left(0.4974 T_{a}\right)-(0.5224 U)=\left(2.8677 Q_{\text {sol ar }}\right) \\
& T_{f 1}=9.1299+\left(0.8023 T_{a}\right)-(0.4084 U)+\left(1.1223 Q_{\text {solar }}\right) \\
& T_{f 2}=14.6351+\left(0.8279 \mathrm{~T}_{\mathrm{a}}\right)-(1.2018 \mathrm{U})+\left(10.3531 \mathrm{Q}_{\text {solar }}\right)
\end{aligned}
$$


Golden Eagles:

$$
\begin{aligned}
& E_{r}=\left(0.0049 T_{a}\right)+(0.0104 U)-\left(U .0618 Q_{\text {solar }}\right) \\
& C_{f}=7.5166+\left(0.0887 \mathrm{~T}_{a}\right)+(0.9480 \mathrm{U})-\left(2.0700 \mathrm{Q}_{\text {solar }}\right) \\
& T_{S 1}=26.5541+\left(0.3988 \mathrm{~T}_{\mathrm{a}}\right)-(0.3945 \mathrm{U})+\left(0.3159 \mathrm{Q}_{\mathrm{solar}}\right) \\
& T_{S 2}=28.0425+\left(0.3216 \mathrm{~T}_{\mathrm{a}}\right)-(0.4601 \mathrm{U})+\left(2.8700 \mathrm{Q}_{\text {solar }}\right) \\
& T_{f 1}=7.6731+\left(0.8410 \mathrm{~T}_{\mathrm{a}}\right)-(0.4277 \mathrm{U})+\left(1.3633 \mathrm{Q}_{\mathrm{solar}}\right) \\
& T_{f 2}=10.7643+\left(0.9246 \mathrm{~T}_{\mathrm{a}}\right)-(1.2869 \mathrm{U})+\left(19.1133 \mathrm{Q}_{\mathrm{solar}}\right)
\end{aligned}
$$


List of measurements (mean species values) used in the heat transfer analysis:

\begin{tabular}{|c|c|c|c|}
\hline Datum & Kestrels & Red-tails & Eagles \\
\hline Body mass $(g)$ & 115.0 & 1145.0 & 4320.0 \\
\hline Body circumference $(\mathrm{cm})$ & 15.9 & 37.8 & 61.7 \\
\hline Body length, base of skull to base of tail $(\mathrm{cm})$ & 9.3 & 19.6 & 29.5 \\
\hline Characteristic dimension (calculation of Reynolds number) & 5.06 & 10.24 & 19.65 \\
\hline Body radius $(\mathrm{cm})$ & 2.53 & 5.12 & 9.83 \\
\hline Feather thickness, back $(\mathrm{cm})$ & 0.90 & 1.45 & 2.25 \\
\hline Feather thickness, breast $(\mathrm{cm})$ & 1.15 & 1.70 & 3.00 \\
\hline Dorsal surface area $\left(\mathrm{cm}^{2}\right)$ & 75.1 & 330.0 & 655.04 \\
\hline Ventral surface area $\left(\mathrm{cm}^{2}\right)$ & 75.1 & 370.0 & 856.4 \\
\hline Scale factor, breast $\left(C_{f 1}=0.5\left(S_{1} C_{f}\right)\right.$ & 0.62 & 0.795 & 0.60 \\
\hline Absorptivity, back (290 to $2600 \mathrm{~nm})$ & 0.681 & 0.770 & \\
\hline Absorptivity, breast (290 to $2600 \mathrm{~nm}$ ) & 0.555 & 0.462 & \\
\hline Absorptivity, wing (290 to $2600 \mathrm{~nm}$ ) & 0.748 & 0.778 & \\
\hline
\end{tabular}




\section{Appendix C}

Example calculation of a scale factor for the kestrel.

$$
C_{f}=\frac{2 \pi K L}{\ln \frac{r_{01}}{r_{i 1}}} \quad+\frac{2 \pi K L}{\ln \frac{r_{02}}{r_{i 2}}} .
$$

If feather thickness is equal,

$$
C_{f}=.5(2 \pi K L)+.5(2 \pi K L) \text {, }
$$

where $L$ is the characteristic dimension (diameter of cylinder representing the bird) and

$$
-1 \quad=\ln \frac{r_{02}}{r_{i 2}} \text {. }
$$

The scale factor for the back is calculated by the following equation:

$$
\frac{\ln \frac{r_{01}}{r_{i 1}}}{\ln \frac{r_{02}}{r_{i 2}}}=\frac{\ln \frac{2.53}{1.38}}{\ln \frac{2.53}{1.63}}=1.38 .
$$

Since

$$
C_{f}=S_{1}(0.5) \frac{(2 \pi K L)}{\ln \frac{r_{01}}{r_{i 1}}}+(1.38)(0.5) \frac{(2 \pi K L)}{\ln \frac{r_{02}}{r_{i 2}}} \text {, }
$$

Calculation of the breast scale factor $\left(S_{1}\right)$ is as follows.

$$
\begin{aligned}
0.5 s_{1} & =(1.38)(0.5) \\
s_{1} & =0.62 .
\end{aligned}
$$




\author{
VITA \\ Steven R. Hayes \\ Candidate for the Degree of \\ Doctor of Philosophy
}

Dissertation: The Combined Effects of Air Temperature, Wind, and Radiation on the Resting Metabolism of Avian Raptors

Major Field: Biology

Biographical Information:

Personal Data: Born at Bremerton, Washington, August 30, 1946, son of Morris and Pauline M. Hayes; married Shirley Ann Stewart, August 31, 1968; three children--Bradley, Devin, and Douglas.

Education: Attended several grade schools on west coast before moving to Fayetteville, Arkansas in 1958. Graduated from Fayetteville High School in 1965; received Bachelor of Science degree from the University of Arkansas, Fayetteville, 1971, and Master of Science degree from the University of Arkansas, Fayetteville, 1974. 